\title{
To study and compare the effectiveness of transobturator tape versus Kelly's repair in the treatment of female stress urinary incontinence
}

\author{
Delina A. Mathias*, Deepali S. Kharat, Michelle N. Fonseca
}

\begin{abstract}
Department of Obstetrics and Gynaecology, Lokmanya Tilak Municipal General Hospital, Mumbai, Maharashtra,
\end{abstract} India

Received: 26 August 2016

Accepted: 03 September 2016

\section{*Correspondence:}

Dr. Delina A. Mathias,

E-mail: delina27@rediffmail.com

Copyright: (C) the author(s), publisher and licensee Medip Academy. This is an open-access article distributed under the terms of the Creative Commons Attribution Non-Commercial License, which permits unrestricted non-commercial use, distribution, and reproduction in any medium, provided the original work is properly cited.

\begin{abstract}
Background: To compare the effectiveness of transobturator tape (TOT) versus Kelly's repair in the treatment of female stress urinary incontinence.

Methods: A retrospective experimental comparative study was conducted in the department of obstetrics and gynaecology in Lokmanya Tilak Municipal General Hospital, Mumbai, India from 2015 to 2016. A cohort of 60 patients was divided in two groups of 30 each. In group 1, patients who underwent transobturator tape fixation were included. In group 2 patients who underwent Kelly's repair and outcomes were compared with a follow up of 1 year post surgery.

Results: Out of 30 patients included in group 1, 29 slings were successful and 1 had a surgical failure in terms of persistence of stress incontinence whereas 3 had persistent symptom in group 2.2 patients in group 1 and 4 in group 2 had urinary retention in the immediate postoperative phase. Dyspareunia occurred in 1 TOT patient and 3 Kelly's repair. None had symptoms of overactive bladder in group 1, whereas group 2 had 1 patient with overactive bladder symptoms. None developed erosion in a 1 year follow up period.

Conclusions: The transobturator approach is an effective treatment of SUI with higher cure rate, low morbidity, good patient satisfaction and faster recovery.
\end{abstract}

Keywords: Stress urinary incontinence, Kelly's repair, Transobturator tape fixation, Surgical outcomes

\section{INTRODUCTION}

Genuine stress incontinence is defined as involuntary loss of urine with increased intra-abdominal pressure in absence of detrusor contractility. Stress urinary incontinence (SUI) has a significant impact on the quality of life for many women. An estimated prevalence for urinary incontinence is nearly $30 \%$ in women aged $30-60$ years, with approximately half of the cases attributed to SUI. ${ }^{12}$ The treatment includes initial conservative therapies (i.e. lifestyle interventions, pelvic floor muscle training, and bladder training), followed by surgery for women whose quality of life is still impaired despite conservative therapy.
ACOG recommendations for stress urinary incontinence are as follows;

- Preoperative multichannel urodynamic testing is not necessary before planning primary incontinence surgery in women with uncomplicated stress incontinence (defined as postvoid urine volume $<150$ $\mathrm{ml}$, negative urine analysis result, positive cough stress test and no pelvic organ prolapsed beyond hymen). Urodynamic testing may be indicated in those with an unclear diagnosis after basic office evaluation (negative cough stress test even with full bladder), symptoms that do not correlate with objective findings, failure to improve with treatment, or prior incontinence or pelvic floor surgery. 
- Approximately $40 \%$ of women without SUI develop symptoms of SUI after surgical correction of pelvic organ prolapse. This condition, known as occult stress incontinence occurs because prolapse kinks and obstructs the urethra and the obstruction is alleviated when the prolapse is repaired. Therefore, all women with significant prolapse should have a preoperative evaluation for occult stress incontinence with cough stress test or urodynamic testing with the prolapse reduced. Women with bothersome stress urinary incontinence who are undergoing pelvic organ prolapse should have concomitant surgery for both.

Kelly's stitch was the most popular primary procedure for stress incontinence up to the 1970 s. The rate of serious complications is less than $1 \%$ and denovo detrussor instability and long term voiding dysfunction are rare however failure rates were found to be high. In France in 2001, Delorme introduced the transobturator sling procedure in humans. ${ }^{3}$ The advantage of TOT sling included avoiding retropubic space therefore less chances of injury to bladder vessel and nerves, less chances of overactive bladder post-surgery and overall decreased operative duration as compared to transvaginal taping (TVT). ${ }^{4,5}$

\section{METHODS}

This is a retrospective comparative experimental study to see the outcome measures in Indian patients attending gynaecology OPD in Sion hospital with SUI treated with TOT versus Kelly's plication in terms of

- Relief of symptoms

- Duration of surgery

- Amount of blood loss

- Duration of hospital stay

- Sexual dysfunction

- Voiding difficulties eg. urgency

- Urinary retention

\section{Inclusion criteria}

- Patients with genuine stress incontinence.

- Patients with coexistent pelvic organ prolapse were included.

\section{Exclusion criteria}

- Patients with history suggestive of urge incontinence.

- Patients who had previously undergone corrective surgery for stress incontinence.

- Pregnant patients.

- Patients not willing for an operative procedure.

- Patients with neurological diseases, psychological illness on antipsychotic drugs and chronic lung diseases.
Group 2: 30 patients who underwent Kelly's repair

Patients were followed up immediate post-operative period on day 7 and at intervals of 3 months, 6 months and 1 year and outcomes in both the groups were studied and compared.

\section{RESULTS}

Out of 30 patients included in group 1, 29 slings were successful and 1 had a surgical failure in terms of persistence of stress incontinence whereas 3 had persistent symptom in group 2 (Figure 1).

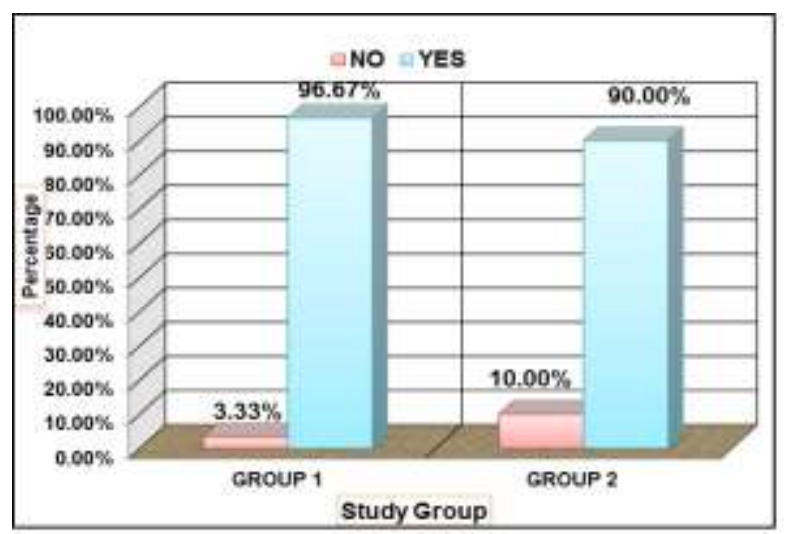

Figure 1: Comparison of surgical outcome among study groups.

2 patients in group 1 and 4 in group 2 had urinary retention in the immediate postoperative phase. Dyspareunia occurred in 1 TOT patient and 3 Kelly's repair. None had symptoms of overactive bladder in group 1, whereas group 2 had 1 patient with overactive bladder symptoms. None developed erosion in a 1 year follow up period. There was no significant difference in the amount of blood loss and operative time in both groups (Figure 2).

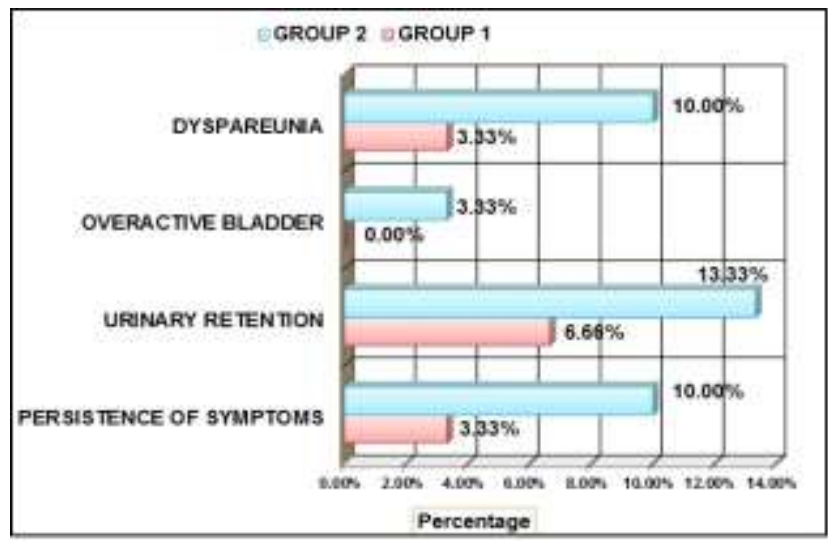

Figure 2: Comparison of post operative complications among study groups.

Group 1: 30 patients who underwent TOT 


\section{DISCUSSION}

In the current study, although there was no significant difference in successful surgical outcome between the two groups, failure rate, duration of hospital stay and associated co morbidities were higher in patients undergoing Kelly's repair. Larger studies though are required to bring forth the significance; this study certainly shows better outcomes in patients with TOT repair.

Delorme reported on 40 patients in whom TOT was applied for the first time, 39 patients had no incontinence post-surgery and 1 patient had improvement in symptoms. ${ }^{3}$ DeTayrac reported a 1-year cure rate of $84 \%$ with the TOT procedure. ${ }^{6}$ In a series of 117 patients with a median follow-up of 16.3 months, Spinosa in reported subjective complete and partial satisfaction rates of $92.3 \%$ and $4.2 \%$, respectively. ${ }^{7}$ Latthe et al quoting their experience in Britain in a series of 135 patients who were applied TOT reported the subjective level of complete cure and improvement reported by patients were $89.6 \%$ and $8.8 \%$, respectively. ${ }^{8}$ Taweel et al reported a $92 \%$ cure or improvement rate after 12 months and $85 \%$ after 24 months by an objective assessment and a patient satisfaction rate of $88 \%$ at 1 year by subjective assessment. ${ }^{9}$

Based on the results of the present study, it may be recommended that transobturator tape approach is a more effective method for treating female stress urinary incontinence in light of the decreased morbidity and increased rate of successful outcome and it has all the potential to be the new Gold Standard in the treatment of female SUI.

Funding: No funding sources

Conflict of interest: None declared

Ethical approval: Not required

\section{REFERENCES}

1. Luber KM. The definition, prevalence, and risk factors for stress urinary incontinence. Rev Urol. 2004;6:S3.
2. Hampel C, Artibani W, Espuña Pons M, Haab F, Jackson S, Romero J, et al. Understanding the burden of stress urinary incontinence in Europe: a qualitative review of the literature. Eur Urol. 2004;46:15.

3. Delorme E. Transobturator urethral suspension: Mini-invasive procedure in the treatment of stress urinary incontinence in women. Prog Urol. 2001;11:1306-13.

4. Kaelin-Gambirasio I, Jacob S, Boulvain M, Dubuisson JB, Dällenbach P. Complications associated with transobturator sling procedures: Analysis of 233 consecutive cases with a 27 months follow-up. BMC Womens Health. 2009;9:28.

5. Latthe P, Foon R, Toozs-Hobson P. Transobturator and retropubic tape procedures in stress urinary incontinence: a systematic review and meta-analysis of effectiveness and complications. BJOG. 2007;114(5):522-31.

6. DeTayrac R, Deffieux X, Droupy S, ChauveaudLambling A, Calvanese-Benamour L, Fernandez H. A prospective randomized trial comparing tensionfree vaginal tape and transobturator suburethral tape for surgical treatment of stress urinary incontinence. Am J Obstet Gynecol. 2004;190:602-8.

7. Spinosa JP, Dubuis PY. Suburethral sling inserted by the transobturator route in the treatment of female stress urinary incontinence: Preliminary results in 117 cases. Eur J Obstet Gynecol Reprod Biol. 2005;123:212-7.

8. Latthe PM, Patodi M, Constantine G. Transobturator tape procedure in stress urinary incontinence: UK experience of a district general hospital. J Obstet Gynecol. 2007;27:177-80.

9. Taweel WA, Rabah DM. Transobturator tape for female stress incontinence: follow-up after 24 months. Can Urol Assoc J. 2010;4:33-6.

Cite this article as: Mathias DA, Kharat DS, Fonseca MN. To study and compare the effectiveness of transobturator tape versus Kelly's repair in the treatment of female stress urinary incontinence. Int $\mathbf{J}$ Reprod Contracept Obstet Gynecol 2016;5:3336-8. 